\title{
PENGARUH CO-CREATION, CURRENCY, COMMUNAL ACTIVITY DAN CONVERSATION TERHADAP CONSUMER JOURNEY.
}

\author{
Devi Krisnawati *) \\ *) Dosen Program Studi Manajemen FE UNKRIS \\ Alamat: Kampus UNKRIS, Jatiwaringin Jakarta Timur \\ Email : devikrisnawati@gmail.com
}

\begin{abstract}
This research use descriptive research with quantitative approach. There are five variables that are used in this research: co-creation, currency, communal activity, conversation, and consumer journey. The collection of data obtained through online questionnaires, which were distributed randomly for six days. The sample in this research was 100 respondents. The sampling technique of this research is random sampling. The data analysis uses descriptive analysis and multiple linear regressions. The results in this research showed that co-creation, currency, communal activity, conversation simultaneously affecting consumer journey significantly. The other results showed that co-creation and conversation partially affecting consumer journey significantly. Otherwise, currency, and communal activity partially were not affecting consumer journey. Based on the result of this research, it's better for a marketer or a company to maintain conversation and develop product with involvement of the customer to strengthen consumer journey.
\end{abstract}

\section{PENDAHULUAN}

Indonesia merupakan negara dengan jumlah pengguna internet terbesar di Asia Tenggara (e-Conomy SEA, 2018), dengan prosentase $42 \%$ dari total pengguna internet di Asia Tenggara. Dalam sepuluh tahun terakhir, penetrasi internet di Indonesia meningkat dari 82 juta ke 171,18 juta jiwa. Di tahun 2018 rasio pengguna internet di Indonesia menyentuh angka $64,8 \%$ dari total populasi penduduk Indonesia yang artinya mencapai 264,16 juta jiwa (APJII, 2019). Berdasarkan pembagian wilayah, pengguna internet di pulau Jawa masih menjadi yang terbesar di Indonesia, yakni mencapai 55\%. Adapun wilayah lain dengan jumlah pengguna internet terbanyak berikutnya adalah Sumatera (21\%), Kalimantan (9\%). Kemudian Sulawesi, Maluku dan Papua (10\%) serta Bali dan Nusa Tenggara (5\%).

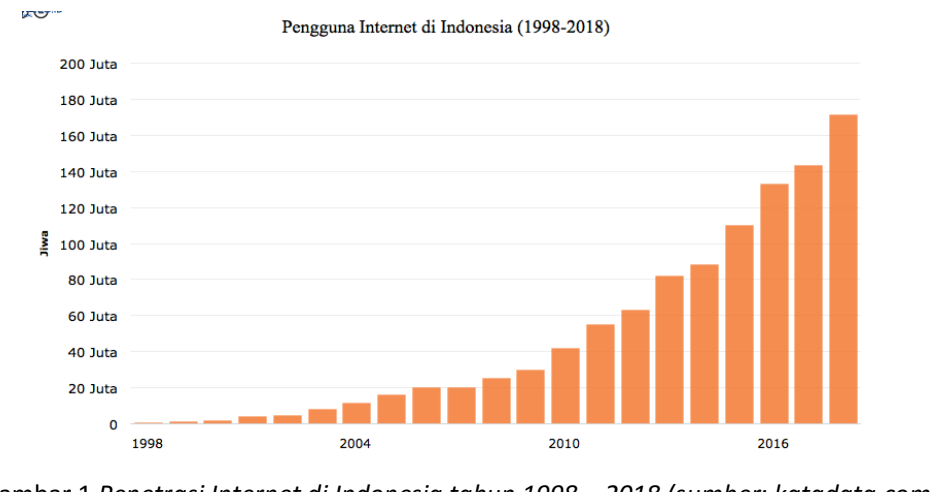

Berdasarkan pembagian usia, menurut survei Asosiasi Penyelenggara Jasa Internet Indonesia (APJII), hampir separuh dari total pengguna internet di Indonesia merupakan kelompok usia produktif, yaitu masyarakat dalam kelompok usia 19-34 
tahun $(49,52 \%)$ dan pengguna internet terbanyak kedua merupakan kelompok usia 3554 tahun $(29,55 \%)$, dimana keduanya memiliki potensi besar sebagai basis konsumsi.

Dari total pengguna internet tersebut, lebih dari 50\% memiliki ponsel pintar. Meningkatnya penetrasi internet di Indonesia tidak lepas dari tumbuhnya pengunaan ponsel pintar berbasis internet itu sendiri. Pada tahun 2017 jumlah pengguna ponsel pintar di Indonesia berada di angka 74,9 juta meningkat sebesar $13 \%$ dari tahun sebelumnya (katadata.com, 2017). Jumlah ini diproyeksikan akan meningkat hingga ke angka 92 juta di tahun 2019. Jumlah basis pengguna internet dan ponsel pintar yang besar ini akan menopang pelaku usaha dalam melakukan aktivitas komersil.

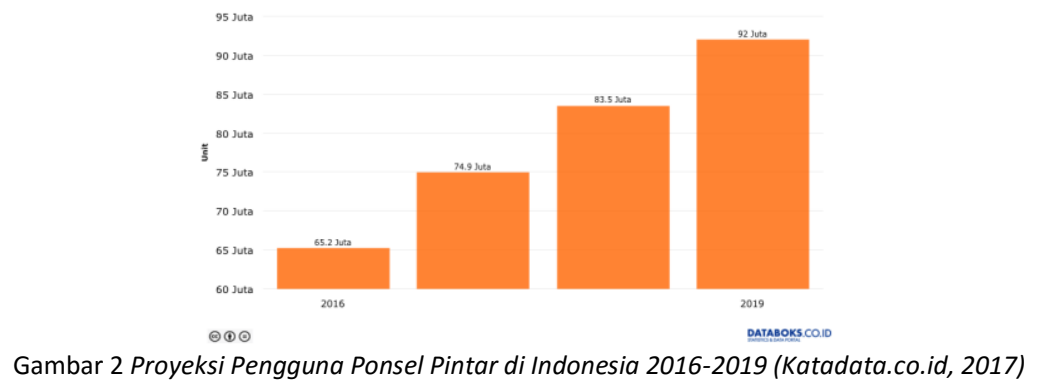

Penggunaan internet dan ponsel pintar dalam setiap kegiatan pada kehidupan sehari-hari menggeser perilaku hidup manusia sehari-hari kepada automation atau kehidupan digital, hal ini tentu juga mempengaruhi perilaku dari para pelaku pasar. Indonesia diprediksi akan menjadi pasar ekonomi digital terbesar di Asia Tenggara dengan nilai 1.449 triliun pada tahun 2025 (Google \& Temasek, 2018).

Perubahan perilaku pada pelaku pasar terjadi juga pada perilaku konsumen digital saat ini. Hal ini tentunya juga merubah pendekatan yang digunakan oleh perusahaan dalam strategi pemasarannya untuk dapat menyasar konsumen saat ini, terutama pada bauran pemasaran. Bauran pemasaran adalah kelompok kiat pemasaran yang digunakan perusahaan untuk mencapai sasaran pemusatannya dalam pasar sasaran. (Kottler, 1995). Bauran pemasaran adalah pencampuran empat elemen strategi pemasaran yaitu produk, harga distribusi dan promosi yang memuaskan segmen konsumen yang terpilih. (Boone \& Kurtz, 1995)

Teknologi digital memungkinkan produsen dan konsumen untuk dapat berinteraksi dua arah pada saat yang sama atau real time sehingga memungkinkan keterlibatan konsumen pada setiap aktivitas pemasaran dengan lebih mudah dan cepat jika dibandingkan dengan sebelumnya, sebelumnya untuk dapat mengakses pasar konsumen harus membuat riset yang terpadu agar dapat mewakili jumlah konsumennya, tentunya hal tersebut membutuhkan banyak sumber daya dan waktu yang tidak sedikit. Pada era digital saat ini, perusahaan dapat mengakses konsumen dan berinteraksi dua arah melalui media sosial. Pada bauran pemasaran sebelumnya, strategi pada produk lebih terpusat kepada kualitas, desain, fitur, dan kemasan yang semuanya disiapkan oleh perusahaan untuk konsumen, insight dari konsumen biasanya didapatkan dari riset yang dilakukan pada tahap awal pembuatan produk, sedangkan saat ini keterlibatan konsumen menjadi utama, dimana konsumen diajak untuk mengembangkan produk yang sesuai dengan keinginan dan kebutuhannya. Harga pada bauran pemasaran digital didefinisikan menjadi currency, faktor harga sebelumnya ditentukan sepenuhnya oleh produsen, saat ini menjadi suatu nilai yang fleksibel, yang dapat ditentukan oleh konsumen juga tergantung pada fitur atau produk seperti apa yang akan mereka beli. Pada teknik distribusi sebelumnya, perusahaan akan menentukan suatu contact point dimana konsumen dapat mencari dan membeli produk, pada era digital saat ini konsumen semakin dipermudah dengan 
adanya pihak-pihak penengah yang menjadi penyambung konsumen dengan produk, seperti maraknya layanan jasa titip yang membuat konsumen tetap dapat membeli produk walaupun jaraknya jauh dari toko, hal ini menjadi mungkin karena konsumen dapat mencari info detail tentang produk melalui web, atau social media. Oleh karena itu, pergeseran cara promosi atau komunikasi antara brand, perusahaan dengan konsumen juga mengalami perubahan signifikan, dengan adanya teknologi digital, suatu brand dapat berkomunikasi dua arah dengan konsumen secara realtime. Konsumen dapat mengakses informasi mengenai produk dan perusahaan dengan mudahnya, kapanpun mereka membutuhkan. Konsumen juga dapat berkomunikasi dengan konsumen-konsumen lain untuk mendapatkan info apapun yang mereka butuhkan. Selain itu, pemberian feedback dari konsumen tentang suatu produk atau brand juga membuat cara promosi suatu produk bergeser dengan tujuan membuat consumer journey atau perjalanan konsumen semakin baik, dengan tujuan akhir bukan hanya sampai di keputusan pembelian namun lebih jauh lagi, yaitu untuk mengadvokasi konsumen lain. Maka dari itu sangat penting untuk perusahaan menciptakan consumer journey yang positif sehingga menghasilkan advokasi positif juga dari konsumen terhadap perusahaan.

Penelitian ini bertujuan untuk mencari pengaruh dari pergeseran bauran pemasaran yang baru terhadap perjalanan konsumen digital, bauran pemasaran digital yang digunakan dalam penelitian ini adalah Co-creation, Currency, Communal Activity dan Conversation yang diduga memiliki pengaruh signifikan pada Consumer Journey.

\section{LANDASAN TEORI}

\section{Connected Marketing Mix}

Teknologi telah membuat proses produksi, pemasaran, distribusi, dan bisnis secara keseluruhan menjadi lebih efisien dan efektif. Konektivitas yang dibangun pun memampukan banyak pelaku bisnis terhubung dengan akses-akses modal dan pasar yang baru. Dalam konteks ini, Philip Kottler menjelaskan sebuah teori Pemasaran 4.0 atau Pemasaran Digital dengan pendekatan pemasaran baru untuk membantu pemasar dalam mengantisipasi dan mengelola dampak teknologi. Konsep tersebut mengkombinasikan interaksi online dan interaksi offline antara perusahaan dengan pelanggan karena pada kenyataannya, justru di saat dunia online berkembang, sentuhan offline menjadi titik diferensiasi yang kuat.

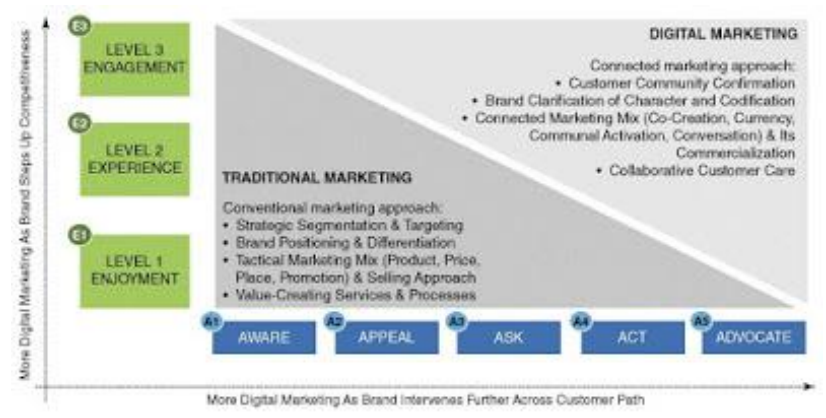

Gambar 3 Pertukaran Peran Pemasaran Tradisional dan Pemasaran Digital (Willey, 2017)

Dalam konsep pemasaran sebelumnya penyusunan strategi pemasaran selalu dimulai dengan Segmentasi pasar, yang kemudian ditajamkan dengan Targeting sehingga bisa mendapakan Positioning Merek yang tajam pula. Dalam konsep 
pemasaran 4.0 segmentasi dan targeting tetap harus dilakukan sebagai fondasi dari strategi pemasaran, namun pada konsep pemasaran digital, hubungan antara merek dan konsumen berada pada lini horizontal yang harus transparan, dimana konsumen yang satu dengan yang lainnya memiliki keterkaitan dan terhubung satu dan lainnya didalam sebuah komunitas. Pada konsep pemasaran digital inilah, komunitas adalah sebuah segmentasi yang baru. Berbeda dengan segmentasi, komunitas sudah terbentuk secara natural oleh konsumen dan berdasarkan kesadaran mereka sendiri. Sehingga untuk bisa dapat berinteraksi dengan efektif pada komunitas konsumen, suatu merk harus meminta izin dan menunggu konfirmasi dari komunitas tersebut. Pergeseran juga terjadi pada positioning merek, dimana sebelumnya suatu positioning adalah ditetapkan untuk memposisikan perbedaan antara merek yang satu dengan kompetitornya, pada konsep pemasaran digital menyebutkan bahwa merk harus bisa lebih dinamis dikarenakan teknologi yang cepat, cycle produk yang lebih pendek, dan pergantian tren yang cepat sehingga suatu merk harus lebih fleksibel menghadapi perubahan namun tetap harus memiliki karakter yang konsisten.

Bauran pemasaran pada konsep pemasaran sebelumnya yang dikenal dengan 4P, yakni Product, Place, Price dan Promotion. Dimana sudah ditentukan oleh perusahaan, walaupun berdasarkan kebutuhan dan keinginan konsumen yang dicari dengan riset pemasaran kemudian ditentukan dan dikemas oleh perusahaan sehingga menjadi sebuah bauran pemasaran yang efektif untuk perusahaan atau merk. Pada konsep pemasaran digital, proses penentuan bauran pemasaran harus lebih melibatkan konsumen. Sehingga marketing mix pada era teknologi digital saat ini di definisikan kembali menjadi 4C, yakni Co-creation, Currency, Communal Activation, Conversation:

\section{Co-creation}

Co-creation sebagai definisi baru dari produk dimana sebuah produk diluncurkan dengan mempertimbangkan keterlibatan konsumen dari mulai proses ide hingga eksekusi untuk pengembangan produk baru, sehingga produk yang ditawarkan oleh perusahaan atau merk menjadi pas dan sesuai dengan kebutuhan konsumen. Selain keterlibatan konsumen pada pengembangan produk baru, co-creation juga berarti melibatkan konsumen dalam memilih barang sesuai kebutuhan dan keinginannya, dimana suatu produk dibuat untuk dapat di kustomisasi oleh konsumen, seperti penambahan fitur, pemilihan tambahan layanan sesuai dengan kebutuhan dan keinginan konsumen. Selain produk kustomisasi (custom-made) indikator dari cocreation adalah personalisasi produk, dimana konsumen dapat terlibat untuk membuat produk tersebut tidak sama dengan produk milik orang lain, seperti penambahan nama atau inisial pada produk, pemilihan warna yang sesuai dengan keinginan konsumen.

\section{Currency}

Currency atau definisi baru dari harga pada bauran pemasaran digital. Harga yang pada konsep pemasaran tradisional ditentukan oleh perusahaan, pada konsep pemasaran digital harga menjadi suatu yang dinamis. Harga yang dinamis tersebut artinya dapat berubah-ubah mengacu kepada permintaan pasar. Beberapa indikator pada variable currency ini adalah fleksibilitas harga dimana harga atau nilai yang menjadi kesepakatan antara penjual dan pembeli pada sebuah produk dapat berbedabeda tergantung dengan permintaan dari pembeli, misalnya pada produk custom atau produk yang dipersonalisasi contohnya, harga yang disepakati akan berbeda tergantung dengan fitur yang dikurangin atau ditambahkan. Selain fleksibilitas harga, indikator dari currency ini adalah harga unik yang berbeda-beda untuk setiap konsumen dan fluktuasi harga sesuai dengan perubahan permintaan pasar. 


\section{Communal Activation}

Pada strategi jalur distribusi pada bauran pemasaran konvensional, perusahaan menyediakan touch point dimana konsumen dapat melihat dan membeli produk, hal tersebut tentu mempengaruhin cakupan pasar dari suatu produk, pada bauran pemasaran yang baru, jalur distribusi tersebut didefinisikan kembali menjadi Communal Activation dimana produsen bukan hanya menyediakan touch point antara konsumen dan merk tetapi membangun kemudahan akses melalui jalur siapapun untuk konsumen dapat mengakses merk. Seperti hadirnya konsep distribusi peer-topeer sehingga proses distribusi menjadi lebih mudah dan cepat. Konsumen saat ini juga tidak hanya dapat membeli produk yang dekat dengannya, tapi juga bisa membeli produk yang jauh dengan bantuan peer atau pihak ketiga yang membuat jaraknya tetap terjangkau.

\section{Conversation}

Conversation, dimana suatu merk bisa mendapat tanggapan langsung dari konsumen terkait dengan kegiatan promosinya, dan kegiatan promosi bisa menjadi lebih dinamis seperti sebuah percakapan. Promosi pada saat ini sudah bukan lagi percakapan monolog antara brand dengan konsumennya, hal ini dimungkinkan oleh platform social media dan platform networking lainnya yang memungkinkan konsumen dapat lebih fokal dalam menyuarakan pendapatnya terhadap brand, disini perusahaan jadi lebih harus hati-hati terkait pengalaman positif yang didapat olen konsumen karena akan sangat berpengaruh kepada feedback terbuka yang dapat diberikan oleh konsumen kepada perusahaan. Indikator yang digunakan pada conversation adalah kemudahan komunikasi dua arah antara konsumen dengan perusahaan, seperti melalui komen pada akun brand atau toko di marketplace. Indikator lainnya adalah komunikasi dari konsumen dengan konsumen lainnya terhadap produk. Indikator selainnya adalah system rating yang memungkinkan pemberian komen dan evaluasi dari konsumen untuk suatu produk.

Dalam konsep Pemasaran 4.0, pemasaran digital tidaklah menggantikan pemasaran tradisional. Sebaliknya, keduanya hadir bersama alias coexist di era sekarang.

\section{Customer Path (Consumer Journey)}

Keduanya saling mengisi peran satu sama lain, khususnya dalam perjalanan pelanggan atau customer path. Pada era digital sekarang ini, customer path telah berubah. Sebelumnya, customer path awalnya dikenal melalui konsep AIDA, yakni Awareness, Interest, Desire dan Action, kemudian berkembang menjadi 4A, yakni Aware, Attitude, Act, dan Act Again. Dalam konsep Pemasaran 4.0 yang dikemukan Kotler, sekarang, perjalanan pelanggan ini berubah menjadi 5A, yakni Aware, Appeal, Ask, Act, dan Advocate. Dalam customer path yang baru ini, pemasaran tradisional dan digital marketing bisa hadir secara bersama. (Willey, 2017) 


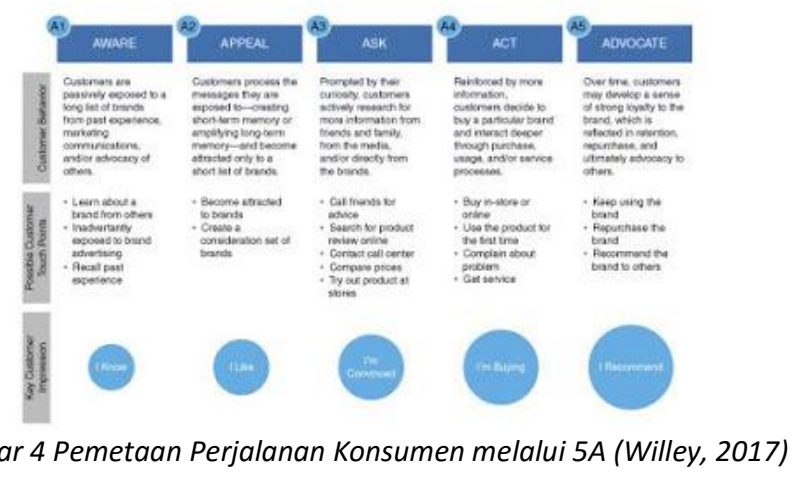

Selain mengkombinasikan online dan offline, teori Pemasaran 4.0 ini juga mengintegrasikan antara style dan substance. Artinya, sebuah merek tidak hanya mengedepankan branding bagus, tetapi juga konten yang relevan dengan pelanggan atau menyuguhkan konten yang bagus dengan kemasan yang up-to-date dan bagus. Selain itu dalam konsep Pemasaran 4.0 selain mengembangkan konektivitas machineto-machine dan artificial intelligence dalam rangka mendongkrak produktivitas yang diwujudkan kuat oleh teknologi digital tetapi juga diimbangi dengan pengembangkan konektivitas human-to-human yang justru akan memperkuat customer engagement.

\section{METODE PENELITIAN}

Penelitian ini menggunakan pendekatan kuantitatif dengan metode pengambilan data menggunakan kuesioner. Sampel yang digunakan pada penelitian ini menggunakan teknik random sampling, dengan jumlah responden sebanyak 100 orang. Penelitian ini menjabarkan data hasil penelitian secara deskriptif dengan metode pengolahan data primer, untuk membuktikan lima hipotesis penelitian yaitu pengaruh empat variable co-creation, currency, communal activity, conversation, terhadap consumer journey sebagaimana digambarkan pada kerangka pemikiran dibawah ini:

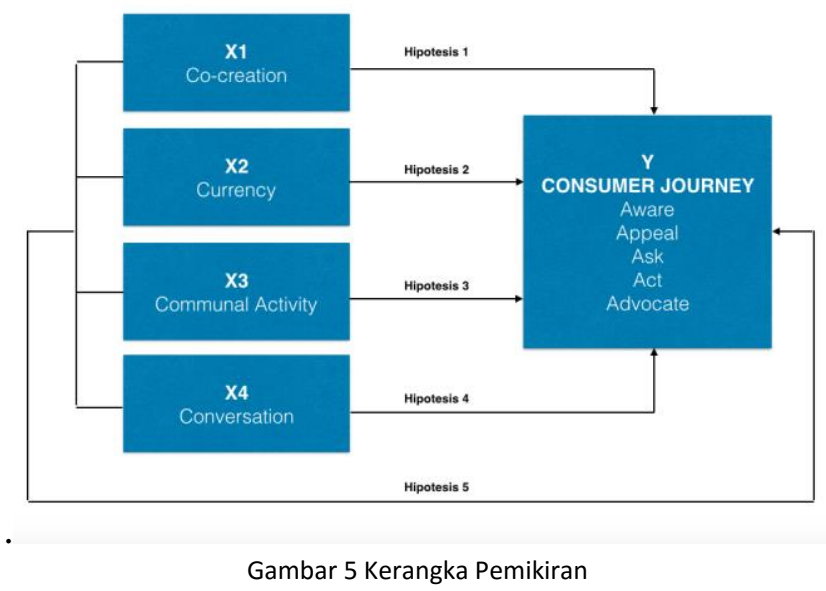

HASIL \& PEMBAHASAN PENELITIAN

\section{Uji Validitas}

Fungsi dari uji validitas adalah untuk mengetahui validasi dari data atau kesesuaian data kuesioner yang digunakan oleh peneliti dalam mengukur dan 
memperoleh data penelititan dari para responden. Sebuah pernyataan dalam kuesioner dinyatakan valid apabila hasil Rhitung $>$ Rtabel dan nilai signifikansi $<0.05$. Pada penelitian ini, Rtabel yang digunakan adalah dengan $\mathrm{N}=100$ pada signifikansi $5 \%$ pada distribusi nilai Rtabel statistic, maka diperoleh nilai Rtabel sebesar 0.1966.

Berdasarkan Hasil uji validitas dari penelitian ini membuktikan bahwa data yang digunakan dalam penelitian ini adalah valid, sebagaimana dijabarkan dengan lebih jelas dalam tabel dibawah ini:

Tabel 1. Hasil Uji Validasi

\begin{tabular}{lcccc}
\hline Pernyataan Survey & Rhitung & Rtable & Sig & Keterangan \\
\hline Pernyataan X1.1 & 0.461 & 0.1966 & 0 & Valid \\
Pernyataan X1.2 & 0.468 & 0.1966 & 0 & Valid \\
Pernyataan X1.3 & 0.448 & 0.1966 & 0 & Valid \\
Pernyataan X1.4 & 0.481 & 0.1966 & 0 & Valid \\
Pernyataan X1.5 & 0.559 & 0.1966 & 0 & Valid \\
Pernyataan X1.6 & 0.602 & 0.1966 & 0 & Valid \\
Pernyataan X1.7 & 0.686 & 0.1966 & 0 & Valid \\
Pernyataan X1.8 & 0.702 & 0.1966 & 0 & Valid \\
Pernyataan X1.9 & 0.719 & 0.1966 & 0 & Valid \\
Pernyataan X2.1 & 0.302 & 0.1966 & 0.002 & Valid \\
Pernyataan X2.2 & 0.546 & 0.1966 & 0 & Valid \\
Pernyataan X2.3 & 0.509 & 0.1966 & 0 & Valid \\
Pernyataan X2.4 & 0.514 & 0.1966 & 0 & Valid \\
Pernyataan X2.5 & 0.606 & 0.1966 & 0 & Valid \\
Pernyataan X2.6 & 0.713 & 0.1966 & 0 & Valid \\
Pernyataan X2.7 & 0.634 & 0.1966 & 0 & Valid \\
Pernyataan X2.8 & 0.676 & 0.1966 & 0 & Valid \\
Pernyataan X3.1 & 0.729 & 0.1966 & 0 & Valid \\
Pernyataan X3.2 & 0.738 & 0.1966 & 0 & Valid \\
Pernyataan X3.3 & 0.215 & 0.1966 & 0.032 & Valid \\
Pernyataan X3.4 & 0.725 & 0.1966 & 0 & Valid \\
Pernyataan X3.5 & 0.719 & 0.1966 & 0 & Valid \\
Pernyataan X4.1 & 0.352 & 0.1966 & 0 & Valid \\
Pernyataan X4.2 & 0.661 & 0.1966 & 0 & Valid \\
Pernyataan X4.3 & 0.725 & 0.1966 & 0 & Valid \\
Pernyataan X4.4 & 0.684 & 0.1966 & 0 & Valid \\
Pernyataan X4.5 & 0.546 & 0.1966 & 0 & Valid \\
Pernyataan X4.6 & 0.471 & 0.1966 & 0 & Valid \\
Pernyataan Y1 & 0.616 & 0.1966 & 0 & Valid \\
Pernyataan Y2 & 0.655 & 0.1966 & 0 & Valid \\
Pernyataan Y3 & 0.757 & 0.1966 & 0 & Valid \\
Pernyataan Y4 & 0.635 & 0.1966 & 0 & Valid \\
Pernyataan Y5 & 0.568 & 0.1966 & 0 & Valid \\
Pernyataan Y6 & 0.711 & 0.1966 & 0 & Valid \\
Pernyataan Y7 & 0.735 & 0.1966 & 0 & Valid \\
Pernyataan Y8 & 0.693 & 0.1966 & 0 & Valid \\
& & & & \\
\hline
\end{tabular}




\begin{tabular}{lcccc} 
Pernyataan Y9 & 0.62 & 0.1966 & 0 & Valid \\
Pernyataan Y10 & 0.725 & 0.1966 & 0 & Valid \\
Pernyataan Y11 & 0.767 & 0.1966 & 0 & Valid \\
Pernyataan Y12 & 0.68 & 0.1966 & 0 & Valid \\
Pernyataan Y13 & 0.614 & 0.1966 & 0 & Valid \\
Pernyataan Y14 & 0.629 & 0.1966 & 0 & Valid \\
Pernyataan Y15 & 0.78 & 0.1966 & 0 & Valid \\
Pernyataan Y16 & 0.768 & 0.1966 & 0 & Valid \\
Pernyataan Y17 & 0.744 & 0.1966 & 0 & Valid \\
Pernyataan Y18 & 0.743 & 0.1966 & 0 & Valid \\
Pernyataan Y19 & 0.749 & 0.1966 & 0 & Valid \\
Pernyataan Y20 & 0.678 & 0.1966 & 0 & Valid \\
\hline
\end{tabular}

Data primer diolah tahun 2019

\section{Uji Reliabilitas}

Sebuah penelitian dikatakan berkualitas jika sudah terbukti validitas dan reliabilitasnya. Uji reliabilitas bertujuan untuk melihat apakah kuesioner memiliki konsistensi jika pengukuran dilakukan dengan kuesioner tersebut dilakukan secara berulang. Uji reliabilitas dapat dilakukan secara bersama-sama terhadap seluruh item kuesioner dalam suatu variabel penelitian. Menurut Sujerweni (2014), kuesioner dikatakan reliable jika nilai cronbach alpha $>0,6$. Pada penelitian ini setiap variabel terbukti reliable dengan penjabaran pada tabel dibawah ini:

Tabel 2. Hasil Uji Reliabilitas

\begin{tabular}{lcccc}
\hline \multicolumn{1}{c}{ Variabel } & $\begin{array}{c}\text { Cronbach } \\
\text { Alpha }\end{array}$ & $\begin{array}{c}\text { Nilai } \\
\text { Kritis }\end{array}$ & N.item & Keterangan \\
\hline Co-Creation & 0.749 & 0.6 & 9 & Reliable \\
Currency & 0.698 & 0.6 & 8 & Reliable \\
Communal Activity & 0.649 & 0.6 & 5 & Reliable \\
Conversation & 0.617 & 0.6 & 6 & Reliable \\
Consumer Journey & 0.945 & 0.6 & 20 & Reliable \\
\hline
\end{tabular}

Data primer diolah tahun 2019

\section{Analisis Regresi Berganda}

Tabel 5 Pengaruh Co-creation, Currency, Communal Activiaty dan Conversation Terhadap Consumer Journey

\begin{tabular}{lccccc}
\hline \multicolumn{1}{c}{ Variabel } & Konstanta & $\begin{array}{c}\text { Koefisien } \\
\text { Regresi }\end{array}$ & $\begin{array}{c}\mathbf{t} \\
\text { hitung }\end{array}$ & $\mathbf{R}^{\mathbf{2}}$ & Sig \\
\hline Co-Creation & & 0.494 & 3.052 & & 0.003 \\
Currency & & 0.321 & 1.576 & & 0.118 \\
Communal & 0.601 & 0.079 & 0.023 & 0.400 & 0.816 \\
Activity & & & & & \\
Conversation & & 1.476 & 4.348 & & 0.000 \\
\hline
\end{tabular}

F hitung $=\mathbf{1 5 . 8 4 0}$

Dependent Variable: Consumer Journey 
Bentuk umum model regresi linier berganda dengan $\mathrm{p}$ variabel bebas pada penelitian ini adalah seperti pada persamaan berikut (Kutner, Nachtsheim dan Neter, 2004).

$$
Y=0.601+0.494+0.321+0.79+1.476
$$

Koefisien regresi untuk co-creation sebesar 0,494, currency sebesar 0,321, communal activity sebesar 0.79 , conversation sebesar 1.476 .

Koefisien regresi co-creation bernilai positif artinya pada saat co-creation naik maka consumer journey juga akan mengalami kenaikan nilai. Begitu pula pada saat co-creation turun maka consumer journey juga turun. Kenaikan co-creation sebesar 1 akan meningkatkan consumer journey sebesar 0,494 dan sebaliknya, penurunan nilai co-creation sebesar 1 akan menurunkan nilai consumer journey sebesar 0,494.

Koefisien regresi currency bernilai positif memiliki arti yang sama dengan koefisien regresi co-creation. Pada saat currency menguat maka consumer journey akan mengalami peningkatan. Begitu pula pada saat currency menurun maka consumer journey-nya juga menurun. Kenaikan currency sebesar 1 akan meningkatkan consumer journey sebesar 0,321 dan sebaliknya, penurunan currency sebesar 1 akan menurunkan consumer journey sebesar 0,321.

Koefisien regresi communal activity bernilai positif memiliki arti yang sama dengan koefisien regresi co-creation dan currency. Pada saat communal activity menguat maka consumer journey akan mengalami peningkatan. Begitu pula pada saat communal activity menurun maka consumer journey-nya juga menurun. Kenaikan communal activity sebesar 1 akan meningkatkan consumer journey sebesar 0,79 dan sebaliknya, penurunan communal activity sebesar 1 akan menurunkan consumer journey sebesar 0,79 .

Koefisien regresi conversation bernilai positif memiliki arti yang sama dengan koefisien regresi co-creation, currency dan communal activity. Pada saat conversation menguat maka Consumer Journey (Y) akan mengalami peningkatan. Begitu pula pada saat conversation menurun maka consumer journey-nya juga menurun. Kenaikan conversation sebesar 1 akan meningkatkan consumer journey sebesar 1.476 dan sebaliknya, penurunan conversation sebesar 1 akan menurunkan consumer journey sebesar 1,476.

Berdasarkan output di atas pada penelitian ini diketahui nilai Koefisien Korelasi (R) sebesar 0,633, hal ini menggandung arti bahwa pengaruh variabel X1, X2, X3 dan X4 secara simultan terhadap variabel $\mathrm{Y}$ adalah sebesar 63,3\%. Dapat disimpulkan derajat hubungannya adalah korelasi kuat

Berdasarkan output di atas diketahui nilai $\mathrm{R}$ Square sebesar 0,4, hal ini menggandung arti bahwa pengaruh variabel X1, X2, X3 dan X4 secara simultan terhadap variabel Y adalah sebesar $40 \%$.

\section{Uji Hipotesis Parsial (UJI t)}

Dalam uji hipotesis parsial, di uji pada masing-masing variabel untuk melihat pengaruh masing-masing variabel $\mathrm{X}$ terhadap variabel $\mathrm{Y}$, jika nilai sig $<0,05$, atau $\mathrm{t}$ hitung $>\mathrm{t}$ tabel maka terdapat pengaruh variabel $\mathrm{X}$ terhadap variabel $Y$. Sebaliknya jika nilai sig $>0,05$, atau $t$ hitung $<\mathrm{t}$ tabel maka tidak terdapat pengaruh variabel $\mathrm{X}$ terhadap variabel Y.

$$
\mathrm{t} \text { tabel }=\mathrm{t}(\alpha / 2 ; n-k-1)=\mathrm{t}(0,025 ; 95)=1.98525
$$


Pada co-creation, nilai sig 0,003 atau lebih kecil dari 0,05 dan nilai t hitung 3,052 atau lebih besar dari t table 1,98525 maka dapat dibuktikan bahwa ada pengaruh antara co-creation terhadap consumer journey.

Sebaliknya, pada currency nilai sig 0,118 atau lebih besar dari 0,05 dan nilai $\mathrm{t}$ hitung 1,576 atau lebih kecil dari pada t table 1,98525 maka currency tidak berpengaruh terhadap consumer journey.

Variable communal activity juga tidak berpengaruh terhadap consumer journey dimana nilai t hitung pada variable X3 adalah 0,233 dimana lebih kecil daripada $\mathrm{t}$ table 1,98525 dan nilai signifikansi 0,816 dimana lebih besar daripada 0,05.

Sedangkan pada variable conversation nilai t hitung adalah 4,348 dimana lebih besar daripada t table 1,98525 dan nilai signifikansi 0,00 dimana lebih kecil dari 0,05 maka dapat disimpulkan bahwa variable conversation memiliki pengaruh terhadap consumer journey.

\section{Uji Hipotesis Simultan (UJI F)}

Pada uji hipotesis simultan di uji apakah ada pengaruh secara simultan antara variable X1, X2, X3 dan X4 terhadap variabel Y. Pada uji f, Jika nilai sig < 0,05, atau $\mathrm{F}$ hitung $>\mathrm{F}$ tabel artinya terdapat pengaruh antara variabel $\mathrm{X}$ secara simultan terhadap variabel $Y$. Sebaliknya jika nilai sig $>0,05$, atau $F$ hitung $<F$ tabel artinya tidak terdapat pengaruh antara variabel $\mathrm{X}$ secara simultan terhadap variabel Y.

$$
\mathrm{F} \text { tabel }=\mathrm{F}(\mathrm{k} ; \mathrm{n}-\mathrm{k})=\mathrm{F}(4 ; 96)=2,47
$$

Pada penelitian ini, merujuk pada tabel diatas $\mathrm{F}$ hitung yang dihasilkan adalah 15,840 dimana lebih besar daripada $\mathrm{F}$ tabel 2,47 dan nilai signifikansi 0,00 dimana lebih kecil daripada 0,05 sehingga dapat disimpulkan bahwa variable X1, X2, X3, dan $\mathrm{X} 4$ secara simultan mempunyai pengaruh terhadap variabel $\mathrm{Y}$ atau bisa dibaca dengan co-creation, currency, communal activity dan conversation secara simultan mempunyai pengaruh terhadap consumer journey.

\section{KESIMPULAN DAN SARAN}

\section{Kesimpulan}

Berdasarkan hasil dari pengolahan data penelitian dapat disimpulkan bahwa: 1). Co-creation berpengaruh signifikan terhadap consumer journey, dimana artinya keterlibatan konsumen terhadap pembuatan hingga pengembangan suatu produk, ruang untuk membuat produk custom dan juga personalisasi pada produk sangat berpengaruh terhadap consumer journey; 2). Currency dalam penelitian ini ditemukan tidak berpengaruh signifikan terhadap consumer journey, artinya faktor harga tidak berpengaruh secara parsial terhadap perjalan konsumen; 3). Communal activity dalam penelitian ini juga ditemukan tidak berpengaruh signifikan terhadap consumer journey; 4). Communication berpengaruh signifikan pada consumer journey, dimana artinya kemudahan akses berkomunikasi dengan brand atau prodok, review dari konsumen lain dan system rating sangat berpengaruh terhadap perjalan konsumen; 5). Co-creation, currency, communal activity dan communication secara simultan berpengaruh terhadap consumer journey.

\section{Saran}

Berdasarkan hasil penelitian ini, teknologi digital dapat menjadi sarana penjualan produk yang potensinya sangat besar. Penggunaan media yang sesuai 
dengan konsumen sangat penting sehingga dapat memberi kemudahan untuk berkomunikasi dengan konsumen, dimana konsumen dapat dengan mudah bertanya atau memberikan feedback pada perusahaan tentang suatu produk dan juga dapat berpartisipasi pada pengembangan suatu produk. Saran untuk penelitian selanjutnya adalah dengan lebih mengeksplorasi media apa yang paling efektif untuk menjadi sarana berkomunikasi dengan konsumen.

\section{DAFTAR PUSTAKA}

Kotler, Philip. Manajemen Pemasaran: Analisis, Perencanaan, Implementasi dan Pengendalian, Jilid I Edisi Bahasa Indonesia, Bandung: Tarsito, 1995

Kotler, Philip; Hermawan Kertajaya; Iwan Setiawan. Marketing 4.0._Willey, 2017

Kotler, Philip dan Gary Armstrong. Prinsip-Prinsip Pemasaran. Diterjemahkan oleh : Bob Sabran. Edisi keduabelas. Jilid 2. Jakarta : Erlangga, 2008

Kerpen, Dave. Likeable Business, the McGraw Hill Company, 2013

https://databoks.katadata.co.id/datapublish/2019/05/16/pengguna-internet-diindonesia-2018-bertambah-28-juta

https://databoks.katadata.co.id/datapublish/2018/02/23/usia-produktif-mendominasipengguna-internet

https://www.cnbcindonesia.com/tech/20190408161849-37-65239/2025-transaksiekonomi-digital-indonesia-bisa-rp-1417-t

http://marketeers.com/pergeseran-perilaku-konsumen-elevenia-dalam-transaksionlinel

https://www.academia.edu/35865427/Pengembangan_Merek_melalui_Personalisasi Kustomisasi_dan_Komunikasi_Kreatif_Brand_Development_through_Personal ization_Customization_and_Creative_Communications

https://news.detik.com/berita-jawa-timur/d-3648994/omzet-bisnis-custom-sangatmenjanjikan

https://kalimantan.bisnis.com/read/20180426/435/788759/dampak-digitalisasimedsos-dorong-ekonomi 